\title{
ANALYSIS OF INFORMATIVE AND PERSUASIVE CONTENT IN PHARMACEUTICAL COMPANY BROCHURES IN LIBYA
} Mustafa Ali Alssageer, Department of Pharmacology, Faculty of Medicine, Sebha University, Sebha, Libya

\section{ARTICLE INFORMATION:}

Article History:

Received: 11 March, 2013

Accepted in revised form: 6 May, 2013

Published: 5 December, 2013

\section{Corresponding author:}

Mustafa Ali Alssageer

E-mail:alssageer68@yahoo.com

\section{Keywords:}

Pharmaceutical company, brochures, advertising, drug information

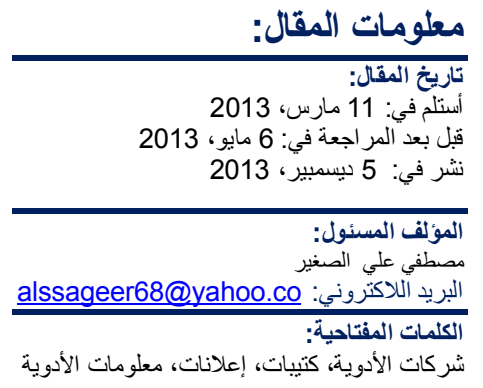

Copyright $\odot$ 2013. LJPCP. This is an open access article distributed under the Creative Comm
use, distribution, and reproduction in any medium, provided the original work is properly cited.

Citation: Libyan J Pharm \&ClinPharmacol 2013, 2: 9511882-http://dx.doi.org/10.5542/LJPCP.v3i0.9511882

(Page numberis not for citation purpose).

دراسة تحليلية لمحتوى المطلومات وطرق الإقتاع في إعلانات كتيبات شركات الأدوية في ليبيا

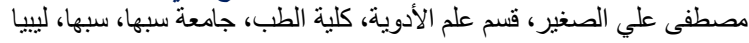

الهلف: دراسة أنماط الأدوية التي بتم الترويج لها في الكتيبات الإعلانية لثركات الأدوية في ليبيا وكذلك نوعية

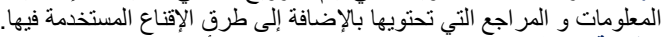

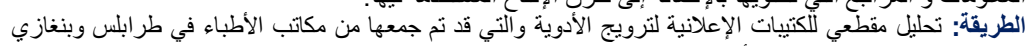

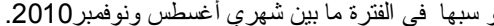

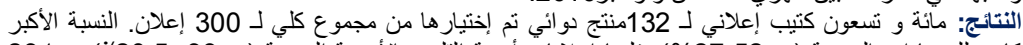

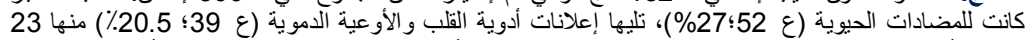

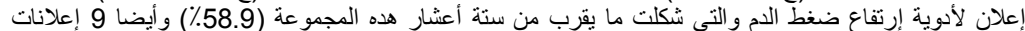

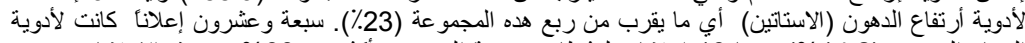

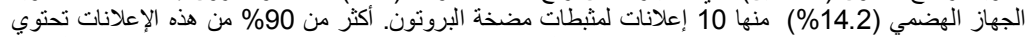

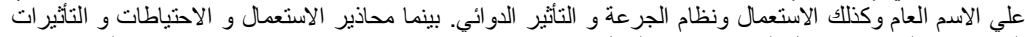

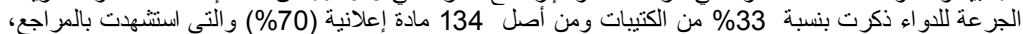

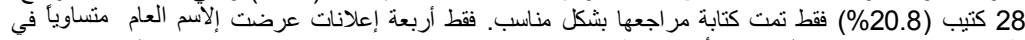

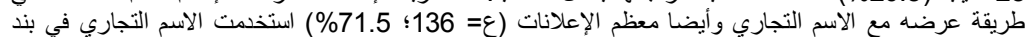

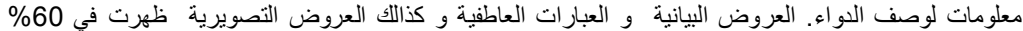

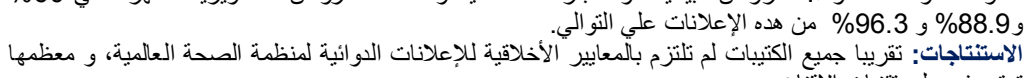
تعتمد في على تقنيات الإقناع.

\footnotetext{
Copyright $\odot$ 2013. LJPCP. This is an open access article distributed under the Creative Commons Attribution 3.0 License, which permits unrestricted
}

\begin{abstract}
ABSTRCAT:
Objective: To examine the patterns of promoted drugs, the quality of information provided, the references cited, and the persuasive techniques used in pharmaceutical brochures in Libya.

Method: Cross-sectional analysis of pharmaceutical brochures collected between August and November 2010 from doctors' offices in three cities: Tripoli, Benghazi and Sebha.

Result: From 300 collected brochures, we took190 promotional materials for 132 promoted products. Antibiotics $(\mathrm{n}=52 ; 27 \%)$ made up the largest proportion.

Cardiovascular products $(\mathrm{n}=39 ; 20.5 \%)$ came next, with antihypertensive agents $(n=23)$ approximately six-tenths $(58.9 \%)$ and statins $(n=9)$ nearly a quarter $(23 \%)$ of that class. Twenty seven products (14.2\%) were gastrointestinal tract agents (GITs) and 10 of the GITs were proton pump inhibiters (PPIs). Over $90 \%$ of brochures provided the generic name, indications, dosage regimen and brief pharmacological effects of the drugs they advertised. However, information on contraindications, precautions, pregnancy and lactation, and adverse effects appeared in only $70.5 \%$ of advertisements. Drug Overdose information appeared in only $33 \%$ of brochures, and out of the $134(70 \%)$ of brochures that cited references, only 28 $(20.8 \%)$ of these brochures cited their references appropriately. Only four of the advertisements displayed the generic name as prominently as the brand name and most $(\mathrm{n}=136 ; 71.5 \%)$ used only the trade name in the prescribing information section. Graphical presentations, emotional texts and pictorial content appeared in $60 \%, 88.9 \%$, and $96.3 \%$ of brochures respectively.

Conclusion: Almost all brochures did not adhere to WHO ethical criteria for drug promotion and mostly relied on persuasive techniques.
\end{abstract}

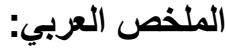

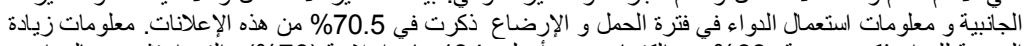




\section{INTRODUCTION:}

A dvertising is a key element of marketing strategy and advertising messages consist of acombination of information and persuasion ${ }^{1}$. Advertising in brochure form is a common "educational" gif supplied by pharmaceutical company representatives (PCRs) during their promotional visits and it can provide written reinforcement of any verbal message provided by PCRs. In Libya, a concurrent study found that $79 \%$ of surveyed respondents reported they were supplied promotional printed material by PCRs during promotional visits ${ }^{2}$ and $94 \%$ of the respondents reported that new information about pharmaceutical products was the main benefit they received from their interactions with $\mathrm{PCRs}^{3}$.A brochure is a passive, convenient source of education and requires little effort to access. It may be tailored to a doctor's request. It provides a summaryof the scientific literature with graphs and references to support its advertising claims. It conveys information to readers in an attractive way since it is designed to be persuasive, with memorable headlines and impressive visuals.

Advertising seeks to increase branda wareness and to change attitude and behaviour. The means of changing someone's attitude is persuasive communication whether verbal or visual ${ }^{4}$. Aristotle ${ }^{5}$ stated that individuals are persuaded based on the credibility of the source, emotional appeals, rational appeals or a combination of these elements.The Elaboration Likelihood Model (ELM) ${ }^{6}$ describes how attitudes can be influenced by persuasive messages. It assumes that there are two routes through which persuasive messages are processed: the central route is depicted by thoughtful consideration and evaluation of the arguments and that attitude shaped from this message is predominantly cognitive. However, in the peripheral route, the reader who is unable to fully process all information received or who is unwilling to engage in a deeper thought process can be persuaded by using 'heuristic' means, such as visual image, tunes, colours, and celebrity endorsements. Pharmaceutical company interaction has been reported as one of the primary influenceon doctors' prescribing decisions $^{7}, 8$. Pharmaceutical companies claim that promotion provides scientific and educational information to the doctors and ensures that patients receive the products they need in the correct dosage with adequate information about the usage of the products in order to ensure a positive health outcome for the patient ${ }^{9}$. Rational responsible prescribing assumes that a medical professional balance the positive and negative features of each product and consider all the alternatives. Pharmaceutical promotional activities are regulated by several international and national guidelines. The World Health Organisation (WHO) and the International Federation of Pharmaceutical Manufacturers Association (IFPMA) establish the standards for ethical promotion of medicines by pharmaceutical companies. They emphasize that promotional practices must be reliable, accurate, truthful and not misleading. In the USA, the Food and Drug Administration (FDA) regulations require that all promotional printed material be accurate, balanced and consistent with the approved therapeutic claims ${ }^{10}$.However, in many countries, pharmaceutical companies do not always comply with these standards. Existing research demonstrates that pharmaceutical drug brochures can provide insufficient ${ }^{11,12}$ and unsubstantiated information ${ }^{11,13}$ as well as vague and misleading claims ${ }^{11,12,14}$, ${ }^{16}$ Libya began privatising the pharmaceutical system in 2003. Pharmaceutical supplies were previously provided to both the public and private sectors by the National Pharmaceutical and Medical Supplies Company, but drug companies are also permitted to market and supply their products to both public and private health sectors through local agencies. In 2009, over 300 international pharmaceutical manufacturers from Europe, Asia and the Middle East were registered as permitted drug suppliers for Libya ${ }^{17}$.In Libya, the quality of drug information of pharmaceutical advertisements is largely unreported. Hence, the aim of this study is to examine patterns of promoted products in pharmaceutical brochures and to evaluate the rationality of drug advertisements in the pharmaceutical brochures by using the WHO guidelines for ethical drug promotion. The study also investigates the prevalence of persuasive techniques and the quality of the cited references in these materials.

\section{METHODOLOGY:}

The design of this study was based on WHO Ethical Criteria for Medicinal Drug Promotion

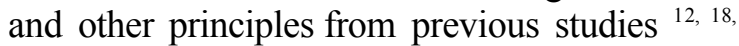

${ }^{19}$.Brochures werecollected from doctors' offices in primary and secondary healthcare institutes in three cities in Libya (Tripoli, Benghazi and Sebha). As a convenience sample, three hundred brochures were collected between August and December 2010.

Brochures were sorted to exclude: 1) Monographs 
2) Reminder brochures with only the name of the product and no risk information or suggestions for use

3) Promotional material for medicinal devices and equipment

4) Pamphlets heightening awareness of particular diseases without mentioning pharmacotherapy

5) Advertisements for cosmetic products.

Duplicates were removed while brochures with different advertisements for the same drug were included. Promoted products were categorised according to therapeuticclasses and their formulation. We examined all the elements of the bro chures and assessed their compliance with the WHO criteria for drug advertisements ${ }^{19}$, Tablela.Citation referencesobtained for assessment were retrieved from Pub Med, the University of South Australia's database or Google search engine. In each piece of advertising, the whole of the written text, photos and graphs and any surrounding material were checked against the criteria for evaluating citations, references, text, graphical information and pictorial persuasive techniques in, Tables1b and1c. We used descriptive statistics for statistical analysis. All values were expressed as frequencies and percentagesin graphs andtables.

Table 1a. Criteria for availability of drug information in brochures were assessed based on WHO criteria (1988) for medicinal drug promotion

- The name(s) of the active ingredient(s) using either international non-proprietary names (INN) or the approved generic name of the drug;

- The brand name.

- Content of active ingredient(s) per dosage form or regimen.

- Mechanism of action

- Pharmacological effect

- Approved therapeutic uses.

- Dosage form or regimen.

- Side-effects and major adverse drug reactions.

- Contra-indications

- Warnings and drug precautions.

- Pregnancy and lactation.

- Major interactions.

- Management overdose.

- Name and address of manufacturer or distributor.

- Reference to scientific literature as appropriate

Table 1b. Criteria for evaluation of references supporting claims in pharmaceutical brochures

- Type of reference (journal article, abstract, books, data on file, government documents, websites, etc.).

- Containing all of the information necessary to identify references. A citation was considered complete if it included, at a minimum, author(s) name, title, publisher, year of publication and volume regardless of the format styles.

- Whether the cited references were retrievable vs. non-retrievable. (Retrievable if soft copy is obtained from the above resources in the internet and non-retrievable if the reference is not available or data on file).

- Whether the study or authors were affiliated with the pharmaceutical industry.

Table 1c. Criteria for analysing presentation styles and persuasion techniques in the textual and pictorial part of promotional brochures.

- Graphs.

- Variation of font headlines between trade names and generic name

- Variation of font size of within the brochure between the prescription information sections vs. the general text (legibility measured as equivalent Arial point size).

- Emotional texts (rhetoric, metaphors and hyperboles words and phrases)

- Using trade name instead of general name in prescription information section.

- Availability of images (products, patient or others).

\section{RESULTS:}

\section{Characteristics of promoted products}

Of 300 collected brochures, 190 promotional materials were evaluated for 132 non-proprietary products(Appendix1).

Outof these 190 brochures, $(n=22 ; 11.5 \%)$ of

advertise ments were combination fixed dose products "multiple active ingredients" compared to168 (88.4\%) were single active ingredients the majority of promoted products $(\mathrm{n}=153 ; 80.5 \%)$ were oral products while external use and parenteral products were $(n=18 ; 9.5 \%)$ for each. Of 132 products identified by a generic name, only 
$25(19 \%$ areon the WHO Essential Medicines list (2011). The largest category of drug was antibiotics $(\mathrm{n}=52 ; 27.3 \%)$, Table2. The most frequently promoted were amoxicillin/clavulanic acid $(n=9)$ and clarithromycin ( $n=7)$, Appendix 1 . The second major category of promoted products was cardiovascular (CV) drugs $(n=39$; $20.5 \%$ ). Over the half of these drugs were antihypertensive agents $(n=23 ; 58.9 \%)$, and angiotensin receptor blockers (ARBs) products $(n=9)$ were the most frequent. Other well-promoted antihypertensive drugs were Amlodipine $(\mathrm{n}=4)$ and Valsartan $(n=3)$. Statins made up (23\%) of the $\mathrm{CV}$ products and atorvastatin appeared five times. Antithrombotic agents made (17.9\%) of the CVs drugs and clopidogrel appeared four times. Twenty seven products $(14.2 \%)$ were gastrointestinal agents (GITs) and PPIs represent 10 products from these GITs. Non-steroidal antiinflammatory drugs (NSAIDs) comprised nearly $10 \%$ of total promoted products $(\mathrm{n}=17 ; 8.9 \%)$. Diclofenac was the most promoted product in this category $(n=4)$ and there was one advertisement for a COX-2 selective inhibitor, Etoricoxib. Oral hypoglycaemic drugs $(n=11)$ were approximately six per cent $(5.7 \%)$ of the total. Glimepiride was found five times (4 times as a single product) and metformin four times (only once as a single active ingredient). Classification of promoted products is presented in, Table 2.

\begin{tabular}{|c|c|c|}
\hline Drug category & $\mathrm{N}$ & $\%$ \\
\hline Antibiotics & 52 & 27 \\
\hline Hypoglycaemic Ags & 11 & 6 \\
\hline Cardiovascular Ags & 39 & 21 \\
\hline GITs & 27 & 14 \\
\hline Analgesics & 17 & 9 \\
\hline Rheumatologic Ags & 5 & 3 \\
\hline Respiratory Ags. & 10 & 5 \\
\hline Dermatologics & 8 & 4 \\
\hline anti-cancer Ags & 6 & 3 \\
\hline Miscellaneous & 16 & 8 \\
\hline Total & 190 & 100 \\
\hline
\end{tabular}

\section{Adherence to WHO criteria for drug advertisements:}

In all the 190 advertisements, the brand name were mentioned in all brochures and $(n=172$; $90.5 \%$ ) mentioned the generic name with the trade name. General information such as the active ingredients appeared in 173 cases (91\%). Indications, dosage regimen and brief pharmacological effects were mentioned in $(\mathrm{n}=174$; 91.5\%), $(\mathrm{n}=173 ; 91 \%)$ and $(\mathrm{n}=178 ; 93.6 \%)$ of cases respectively. The availability of this in formation is summarised in, Figure1. Safety informationoncontraindications, precautions, preg- nancy and lactation, and adverse effects information were presented in these advertisements as $(\mathrm{n}=135 ; 71 \%),(\mathrm{n}=134 ; 70.5 \%),(\mathrm{n}=131 ; 69 \%)$ and $(\mathrm{n}=136 ; 71.5 \%)$ respectively. Major interactions information was less presented $(n=107$; $56.3 \%$ ). Mechanism of action and overdose management were also presented frequently- in just under one half $(n=93 ; 49 \%)$ and one third $(n=63 ; 33 \%)$ of the advertising materials respectively, Figure 1. Out of the $134(70.5 \%)$ of brochures that cited references, only 27 (20.1\%) of brochures cited their references in appropriate format.

\section{THE STUDY'S MAIN FINDINGS:}

- Pharmaceutical brochures information is not always accurate or unbiased

- Emotional statements and visual contents in brochures are pervasive, persuasive, recall-inducing and influential.

- Pharmaceuticaladvertisements should adhere to the international ethical standards of pharmaceutical promotion.

- An approved codeof conduct for pharmaceutical

promotional activities needs to be established in Libya

\section{References:}

The 190 promoted brochures gave a total of 750 References; an average of approximately 4 references each (range from 1 to 24). Of these references claims, only two-thirds $(n=505,67.3 \%)$ were retrievable. Of the 505 verifiable references,journal articles were $(\mathrm{n}=347 ; 69.2 \%)$,

Abstracts $(\mathrm{n}=137 ; 26.7 \%)$, books $(\mathrm{n}=12 ; 2.3 \%)$ and websites $(\mathrm{n}=9 ; 1.7 \%)$. Of the 347 journal articles cited in support claims, $(\mathrm{n}=211 ; 60.8 \%)$ were funded by pharmaceutical companies, or the authors were affiliated with those companies, Table3. Of 243 non retrievable references, 158 were incomplete $(65 \%)$ and data on file $(n=33$, $13.5 \%)$ while only $(n=40 ; 16.3 \%)$ of these references were cited in complete format. Non English language references were reported in 7 references $(2.8 \%)$. In general, $(\mathrm{n}=217 / 750$, $29 \%$ ) of the cited references whether retrievable or non-retrievable were complete reference formats, Table3. Only one of these brochures achieved full compliance with the WHO criteria. 


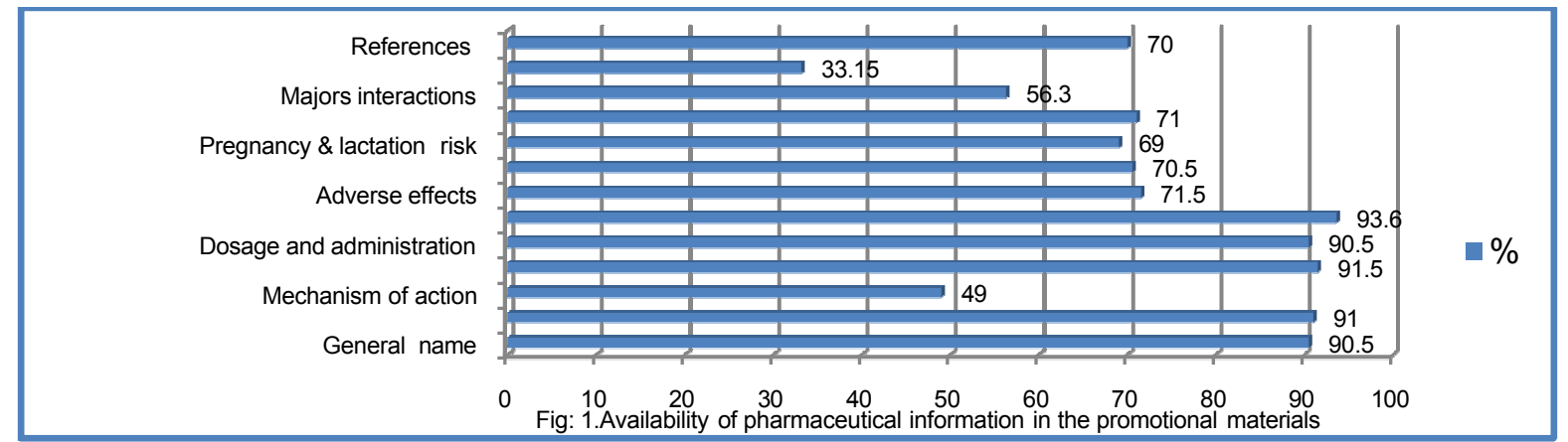

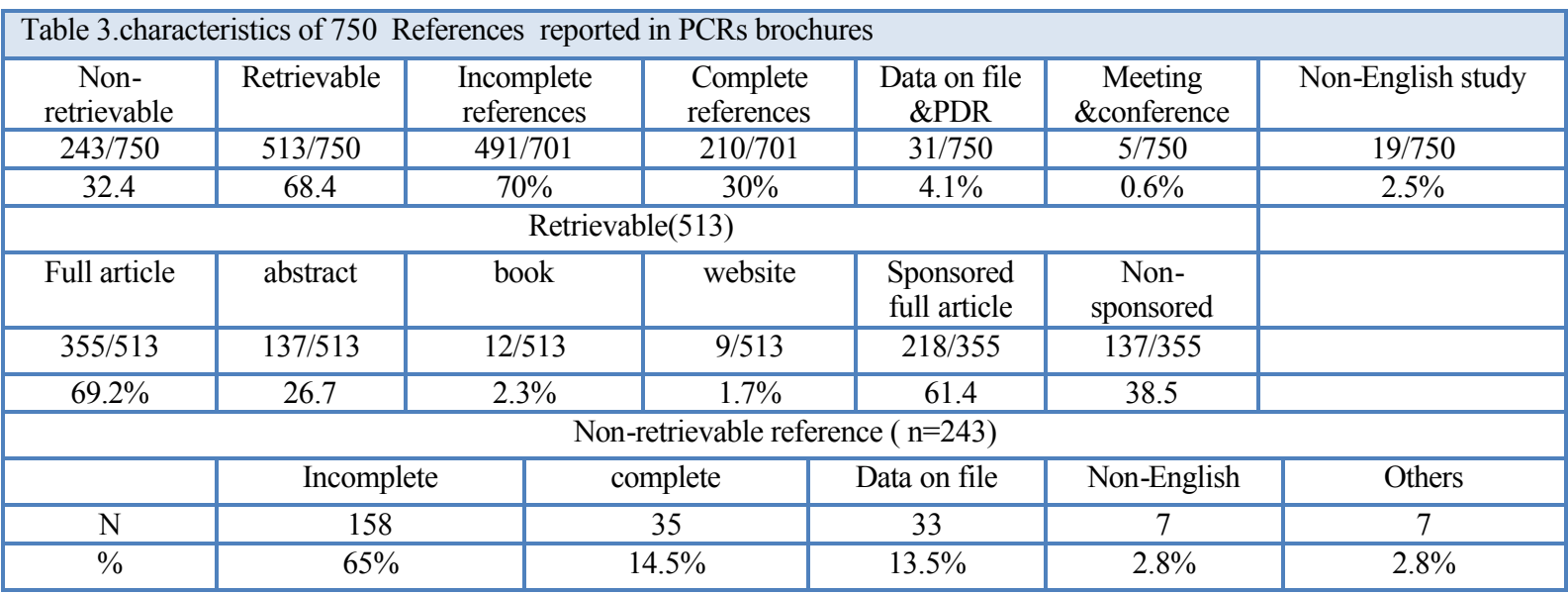

\section{Persuasive techniques used in brochures:}

Graphical presentations were displayed in $(n=114 ; 60 \%)$ of promotional brochures. Of 190 surveyed brochures, only $(n=4 ; 2.3 \%)$ of the advertisements displayed the generic name as prominently as the brand name. The majority of the $190(\mathrm{n}=136 ; 71.5 \%)$ used only the trade name instead of the general name in the context of prescribing information section, Table 4. The majority of prescribing information $(n=118$; $62 \%$ ) appeared in a font size less than the main body text, and almost a half of brochures(49.4\%) used a font size less than eight point. One in eight $(n=24 ; 12.6 \%)$ dropped to six points or below (Arial font readability equivalent).The majority of printed materials had pictorial information "pictures" $(\mathrm{n}=183 ; 96.3 \%)$ and emotional statements $(\mathrm{n}=169 ; 88.9 . \%)$, Table4. Most pictures showed the promoted products $(n=150$, $78.9 \%$ ) and a large proportion of also showed the patient or end user of the products $(n=76$; $40 \%$ ). Less frequently, pictures focused on the site of drug action $(n=26 ; 13.7 \%)$. There were also a few brochures with other illustrations such as cartoons, landscapes or animals.

\begin{tabular}{|l|l|l|}
\hline Table 4. categorisations of visual and verbal contents of pharmaceutical brochures & $\mathrm{N}$ & $\%$ \\
\hline Name & 183 & 96.3 \\
\hline Pictures & 114 & 60 \\
\hline Graphs & 169 & 89 \\
\hline Emotional phrases(metaphors, exaggerations) & 136 & 72.5 \\
\hline Frequent using Trade name PI & 186 & 97.8 \\
\hline Font and style of trade name different from the general name of promoted & 94 & 49.4 \\
\hline Font of PI text (4-8) Arial & 118 & 62 \\
\hline Font PI less than the major body text & \\
\hline PI: Prescription Information. & \\
\hline
\end{tabular}

\section{DISCUSSION:}

As far as we know, this is the first study in Libya to focus on quantitative aspects of the information and persuasive content in pharmaceutical brochures circulated to doctors' offices by PCRs. The different categories of drugs in the pharmaceutical brochures in this study provided an insight into the marketing of drugs in Libya. The majority of promoted drugs $(80.5 \%)$ were oral dosage form and a minority $(9.5 \%$ each) for external and parenteral use. A similar trend was reported in a study in Zimbabwe ${ }^{12}$ in which oral dosage products accounted for $61 \%$ of the total 
advertising, followed by parenteral preparations (22\%) and topical preparations with only $4 \%$. This trend is not unexpected since the oral route, in general, is the most convenient and usually the safest and least expensive for the patient. For rational drug use essential drugs must be available ${ }^{21}$. All of the promoted products in these brochures are produced by foreign manufacturers. The study found that only 25 items from 132 promoted products consistent with the WHO's list of essential medicines. The Libyan Health Law, act number 106 of 1973 and its explanatory notes of 1975, states that registration of medicines with the Libyan Ministry of Health should precede the availability of any medicine in the Libyan market. Since all the promoted drugs assumed to be approved by the ministry of health, one may raise question as to whether these products cover the essential drugs needed in Libya. Full discussion about the selection process of the list of essential medicines is beyond the scope of this paper. The study revealed that anti-infective agents had the highest rate of promotion (27\%), particularly the three classes: B-lactams, macrolides and quinolones. Amoxicillin/clavulanic acid, and clarithromycin antibiotic were the most frequently promoted products of all. This promotion of antibiotics is consistent with the trend of drug prescriptions in Libya. A previous study reviewed 700 prescriptions from Tripoli and Alzawiya and found $25 \%$ of prescribed medicines were antibiotics ${ }^{22}$. Another retrospective drug utilization study in different wards of Zawiya TeachingHospital ${ }^{23}$ found that amoxicillin/clavulanic was the most-used antibiotic in two consecutive years, 2008 and 2009. The current study did not assess the relationship between the written information provided by the PCRs and doctors' prescribing behaviour. However, Zoutman, et al. ${ }^{24}$ assessed antibiotic prescribing for upper respiratory tract infections (URTIs) by family doctors and the subsequent influences on antibiotic prescribing and found that doctors who relied on commercial information sources, such as PCRs, were more likely not to prescribe first line antibiotics for acute sinusitis. The current study found that broad spectrum antibiotics were more frequently promoted than narrow products. In Libya, there are no national therapeutic guidelines or policy for rational prescribing of antibiotics. Overuseof antibiotics,particularlybroad-spectrum antibiotics, in primary care is a major contributing factor to increased prevalence of resistant pathogens in the community ${ }^{25}$.Of the cardiovascular medications $(n=39 ; 20.5 \%)$, antihyperten- sives were the most promoted subclass $(n=23$; $58.9 \%$ ), and $\mathrm{ARBs}$ were the more frequently advertised $(n=9)$ than other antihypertensives. Consistently, the increased use of gastrointestinal drugs was driven by increased advertising of PPIs. We found that PCRs are more likely to promote new generation products like broad spectrum antibiotics, anticoagulants, antihypertensives, statins, andPPIs, than existing drugs. Doctors' choices of drugs are influenced by perceived pharmacological advantages and cost effectiveness over the alternatives. Newer drugs sometimes offer improvements over existing therapies. However, a study in Canada ${ }^{26}$ assessed 1147 new products showed that only $142(12.3 \%)$ were the drug of choice to treat effectively a particular illness or to provide a substantial improvement over existing drugs. Previous studies ${ }^{27}, 28$ reported that claims about new drugs may be inaccurate or biased and may encourage usage of more expensive branded drugs. Recently (2012), the United States Justice Department fined the GlaxoSmithKline (GSK) company \$US 3 billion for unlawfully promoting unauthorized uses "off-label use" of paroxetine and bupropion, and for failing to report safety data about the controversial GSK diabetes drug rosiglitazone. The aggressive promotion of new drugs suggests that the new drugs are superior to existing products despite doubts in the literature about their actual value ${ }^{29}$. Prescribing new and expensive drugs because of pharmaceutical marketing is the main reason for rising prescription expenditures. The effectiveness of drug detailing is directly dependent on the quality of drug information provided and this will have a direct effect, positively or negatively, on doctors prescribing decisions. Rational prescribing assumes that a medical professional balances the positive and negative features of each product and considers all the alternatives. Brochures should contain all relevant and pertinent scientific information. In this study, almost all brochures fail to comply with the WHO Ethical Criteria for Medicinal Drug Promotion. They provide unbalanced information about their products. Information regarding indication, dosage regimen and pharmacological properties was satisfactory in most cases $(>90 \%)$. However, safety information which may discourage use of a drug was less frequently presented. The risk information (contraindications, pregnancy and lactation information, precautions, adverse effects and major interactions) were reported in average $67.7 \%$ of the promoted literatures. This finding matches another study conducted in Libya in (2010) in 
which $41-65 \%$ of the medical practitioners surveyed reported that PCRs rarely or never mentioned safety information ${ }^{30}$. To omit safety information can negatively impact on rational drug prescribing decision and patient healthcare outcome. In this study, $30 \%$ of brochures $(n=56)$ did not contain any reference to support the claims. Similar finding were also observed in other studies $^{31,33}$.Pharmaceutical companies provide bibliographical references in brochures of promoted products to giveapparent respectability and credibility to the advertisements. However, the quality of these references varies widely and some are not readily accessible. A systematic review study by Othman et al. ${ }^{34}$ found that citation errors are widespread in pharmaceutical company advertisements worldwide. This study found that nearly one third $(32.6 \%)$ of the total references $(\mathrm{n}=750)$ could not be retrieved. Further analysis revealed that the majority of non retrievable references $(n=158 ; 65 \%)$ contained only partial bibliographic information, compared to $16.3 \%(\mathrm{n}=40)$ completely formatted. Also a considerable number came from private sources such as industrial data on file $(n=33 ; 13.5 \%)$, which is in most cases not available from pharmaceutical companies when it is requested ${ }^{31,35}$.It is also noteworthy that presenting a citation does not mean that the claims in advertisements are valid. Lankinen et al. ${ }^{36}$ found in that all of unambiguous claims by pharmaceutical companies did not cited with strong scientific evidence but they had relatively more supporting references than other claims. Therefore, regardless of the claims in an advertisement, high-quality citations are crucial for credibility, and if the cited reference is nonretrievable, the information is unreliable. Full bibliographic information enables health professionals to check validity of the claims in the brochures. In this study, the majority of references of journal researches 218 (61.4\%) involved work sponsored by or authors affiliated to pharmaceutical companies compare the figure of $58 \%$ from Cooper et $\mathrm{al}^{31}$. In a systematic review ${ }^{37}, 16$ studies assessed the relationship between the outcome and source of funding. This review found that 13 studies revealed the existence of relationship between funding by pharmaceutical industries and the trial outcomes in favour of their funded products. Funding predicates bias, one might say. Another two studies ${ }^{35,38}$ found the majority of pharmaceutical advertisements to be based on studies of poor methodological quality. Therefore, concerns about brochures are well established. The current study found that graphical data ap- peared in nearly two thirds of the surveyed brochures $(n=114 ; 60 \%)$. Remarkably, this percentage is quite high compared to another study done in India which found only $15.9 \%$ had graphs ${ }^{39}$. The visual approach communicates information summarises outcomes and simplifies the content of the advertisement. However, these graphs also may misrepresent data, leading to wrong inferences and incorrect conclusions. Cooper et al. found that of 74 graphs in medical journals, $8 \%$ had errors, $5 \%$ were visually confusing and $12 \%$ did not follow standard graphing techniques. Another study ${ }^{40}$ reported that necessary information such as confidence interval of $p$ value, power calculations and "number needed to treat" were often missed in pharmaceutical advertisements. It is important to note that the compliance of the content of pharmaceutical brochures for WHO essential criteria does not guarantee the safety or the effectiveness of promoted products. Since doctors are busy professionals, they may have little capacity to process abundance of advertising messages and editorial content. Under such circumstances, brand awareness, knowledge, and images affect doctors' cognitive beliefs leads to sympathy for the brand and brand preference, which in turn affects prescribing habits ${ }^{41}$. The way information is presented can greatly affect the cognitive activity of audience receiving it. Brochures incorporate various psychological and emotional techniques to persuade the reader. The primary purpose of drug advertisements is to create product awareness, attract attention, arouse interest, create positive attitudes, and influence prescribing decision. The persuasive aspects of both visual and text elements characterised most of the brochures. In advertising techniques, the font sizes, pictorials, headlines and body text of the brochures all have specific marketing influence. Hence, the level of understanding and comprehension of the advertisement are prerequisite into the consumer memory and change their attitude $^{42}$. Consequently, clear writing captures the reader's attention and legible text is essential for speed and comprehension ${ }^{43}$. This study found that product-favouring information, such as trade name, pharmacological efficacy and emotional words and phrases about uniqueness, were presented in text with larger font size than generic drug names or the prescribing information sheets. Headlines draw attention and increase the persuasive connection with the brand name. A prominent brand name is easily to recall and retrievable while writing a prescription than general name. However, the smaller font size used for generic 
information distracts attention from it and affects the capability of the information sheet to be comprehended properly. The decision making process can be influenced by retrieval of brand information from memory and this knowledge can be acquired from sources in the external environment. Busy practicing physicians are more likely to extract the information quickly and indistinct print decreases the interaction of readers with it. Advertising research confirms that frequent exposure to advertisements increases brand awareness ${ }^{44,45}$. Over the half of brochures use the trade names instead of general name in the prescribing information sections. In the same way as with the font size, improving the memory of the brand name of the promoted product increases the chance of this brand name being prescribed by the doctor.

\begin{tabular}{l} 
LIST OF ABBREVIATIONS: \\
PCR: Pharmaceutical Company Representative. \\
WHO: World Health Organization. \\
IFPMA: International Federation of Pharmaceutical Manufac- \\
turers Association. \\
FDA: Food and Drug Administration. \\
PPIs: Proton Pump Inhibitors \\
ARBs: Angiotensin Receptor Blockers \\
GITs: Gastrointestinal Tract Agents \\
COX2: Cyclooxygenase2 \\
URTIs: Upper respiratory tract infections \\
PDR: Physician's Desk Reference \\
\hline
\end{tabular}

Using branded drugs instead of generics is one of the reasons for rising prescription expenditures ${ }^{46}$. Steinman et al. ${ }^{47}$ examined the frequency of physicians using brand or generic terminology for prescription medications. They found $79 \%$ of prescriptions used brand names and had a generic equivalent at the time of the survey. In Libya a study ${ }^{22}$ found only $10 \%$ of medicines were prescribed by generic name. This lower rate in Libya may be attributed to the influence of the interaction of prescribers with PCRs. On the other hand, this could be also attributed to money spent on brand-name promotion. In the United States, the FDA recommends that generic name should have a prominence equal to that of the brand name including all printing features. If the running text spans more than one page, it also recommends that the established name accompany the generic name at least once per page ${ }^{48}$.Physicians want medicines to be safe, effective, tolerated, and acceptable to patients. Advertisements use several means such as pictures or emotive words to associate the brand name with these features. Pharmaceutical companies use a unique brand identity to differentiate their products from the competition and also use emotional phrases or pictures subliminally to stimulate the cognitive process ${ }^{49}$. We found visual images $(89 \%)$ or emotional texts $(87.3 \%)$ in almost all of the brochures. All these marketing aspects are designed to work together to persuade physicians to prescribe a promoted product. In other words, repetition of the same message in different ways augments the value of the original message .Pictures provide motivation for readers to read and comprehend the brochures $^{49}$. They are more understandable and more readily absorbed than similar message presented only in words since the pictures likely activate a visual as well as a verbal encoding process ${ }^{50}$. Pictures also create a positive attitude and more cognitive elaboration through emotional affects and the reinforcement of verbal text ${ }^{51}$. For instance, pictures of the promoted products ( $78 \%$ of total brochures) make implicit a set of unique associations with brand name and company product which are easily coded in the visual memory of the prescriber and which may take a longer time to deteriorate from the brain than text messages do. Similarly, pictures that imply superior patient healthcare outcome were found frequently in brochures $(40 \%$ of total brochures). These emotional affects in advertisements are comprehensive, memorable and influential and divert the prescribers from a merely medical context to a socioculturalperspective ${ }^{52}$. Less frequently, brochures have informational pictures such as the mechanism or site of drug actions $(n=26 ; 14 \%)$. There are several implications that can be derived from this research. The quality of information provided during drug detailing visits has repercussions for adopting or not adopting a particular drug ${ }^{30}$. In many developing countries, rational prescribing guidelines are either unavailable or not effectively implemented and PCRs are frequently the only source of drug information ${ }^{53}$. In absence of an independent source of drug information, as in Libya, commercial information tends to replace retrieval based evidence. Earlier studies reported that PCR interactions with doctors can have a negative impact on prescribing practice ${ }^{54}$. Our findings highlight the current state of pharmaceutical promotion in Libya and offer policy makers insight into areas for improvement. To ensure balanced information and consistent standards about promoted products needs a continuous process of monitoring, evaluation and appraisal of pharmaceutical advertisements by the health professional disciplines. Omitting specific requirements of information sheets such 
as contraindications and adverse effects may be judged as breaching the Code of Practice. Hence, prescription information should include a clear statement for each requirements of drug information sheets according to $\mathrm{WHO}$ criteria, even if that information is non-applicable or unreported, to avoid missing any important elements. Most pharmaceutical brochures use emotional claims in promoting company products to reinforcetheir persuasive messages. Unethical pharmaceutical promotion and low quality of drug information lead to irrational prescribing of drugs. Physicians may underestimate or be unaware of hidden messages in images and emotional texts in advertisements, which can create a positive attitude toward promoted products. Physicians need to assess carefully the emotional statements and images in drug promotional literature before making any decisions based on them. Government and national medical agencies should also take practical positions in monitoring pharmaceutical promotion activities to ensure consistent standards and appropriate control of drug advertisements. Another problem that needs specific attention is that the Libyan regulations for pharmaceutical promotion urgently need to be reformed and updated, consistent with recent developments in pharmaceutical drug marketing. All drug advertising should include risk information and provide complete scientific evidence in citations that (a) actually support the claims and (b) can actually be retrieved. Claims should be balanced and factual without emotional information.

\section{CONCLUSION:}

The common promoted products are antibiotics, cardiovascular drugs and PPIs. Almost all the circulated brochures of PCRs did not provide essential information recommended by WHO ethical criteria for medicinal drug promotion, with widespread citation errors in bibliographic references. The majority of pharmaceutical brochures employ persuasive techniques in their marketing, designed to be memorable and influential.Pharmaceutical companies should closely scrutinise their printed advertisements to ensure their content complies with international standards. Since the assessment of the rationality of promotional materials requires scientific skills, we support the idea that health professionals should be educated about critical appraisal and evaluation of evidence. This may also teach health professionals about marketing techniques and help them to attend more closely to visual presentations and to analyse them more critically.
Limitations: There are limitations to this study. The validity of the study results may be limited by the number of pharmaceutical brochures surveyed. The generality of our results is uncertain because we focused only on advertisements in Libya in 2010. The aim of this study was not to directly and objectively assess the accuracy and efficacy of the information provided by PCRs. We did not assess whether the references adequately substantiated each claim made in the advertisements. We did not attempt to request data on file from pharmaceutical companies. Although we investigated all journal advertisements in the database of the University of South Australia, this may not reflect the content of other databases or other types of electronic libraries. Hence, the use of a single database to assess the retrievability of references could be also considered a potential limitation.

\section{CONFLICT OF INTEREST:}

The authors have not received any funding or benefits from industry or elsewhere to conduct this study.

\section{REFERENCES:}

1) Ferner RE, Scott DK. Whatalotwegot--the messages in drug advertisements. BMJ. 1994 Dec 24-31; 309(6970):1734-6.

2) Alssageer MA, Kowalski SR. A survey of pharmaceutical company representative interactions with doctors in Libya. Libyan J Med.2012;7 3) Alssageer M, Kowalski S. What do Libyan doctors perceive as the benefits, ethical issues and influences of their interactions with pharmaceutical company representatives? The Pan African Medical Journal. 2013; 14:132.

4) Cialdini RB, Petty RE, Cacioppo JT. Attitude and attitude change. Annual Review of Psychology. 1981; 32:357-404.

5) Larson C. Persuasion: Reception and Responsibility. 10th ed. 2004: Belmont: Wadsworth/Thompson Learning. 404p.

6) Petty RE, Cacioppo JT. Attitudes and Persuasion: Classic and Contemporary Approaches.Dubuque:Westview Press. 1996.

7) Ben Abdelaziz A, Harrabi I, Rahmani S, Ghedira A, Gaha K, Ghannem H. Attitudes of general practitioners to pharmaceutical sales representatives in Sousse. East Mediterr Health J. 2003; 9:1075-83.

8) Kisa S. Factors that Influence Prescribing Decisions among Turkish Physicians. Clinical Research \& Regulatory Affairs. 2006;23 (3/4) : 177-89. 
9) Spurling GK, Mansfield PR, Montgomery BD, Lexchin J, Doust J, Othman N, Vitry AI. Information from pharmaceutical companies and the quality, quantity, and cost of physicians' prescribing: a systematic review. PLoS Med. 2010 Oct 19;7(10):e.

10)O'Malley K, O'Hanrahan M. Drug promotion and the doctor.Br J Clin Pharmacol. 1982 Nov;14(5):661-4.

11)Keng A, Coley RM. Evaluating the accuracy of citations in drug promotional brochures.Ann Pharmacother. 1994 Nov;28(11):1231-5.

12)Sibanda N, Gavaza $P$, Maponga CC, Mugore L.Pharmaceuticalmanufacturers' compliance with drug advertisement regulations in Zimbabwe.Am J Health Syst Pharm. 2004 Dec 15;61(24):2678-81.

13)Tuffs A. Only $6 \%$ of drug advertising material is supported by evidence.BMJ. 2004 Feb 28;328(7438):485.

14)Als-Nielsen B, Chen W, Gluud C, Kjaergard LL. Association of funding and conclusions in randomized drug trials: a reflection of treatment effect or adverse events?JAMA. 2003 Aug 20;290(7):921-8.

15) Rohra DK, Gilani AH, Memon IK, Perven G, Khan MT, Zafar H, Kumar R. Critical evaluation of the claims made by pharmaceutical companies in drug promotional material in Pakistan. J Pharm Pharm Sci. 2006; 9(1):50-9.

16)Islam, MS, Farah SS. Drug promotional brochure as a source of drug information in Bangladesh: a critical analysis of the brochures. Calicut Medical Journal. 2008; 6(1):e5.

17)The Australian Trade Commission. Health and medical to Libya. Available from: http://austrade.gov.au/Health-and-medical-toLibya/default.aspx [downloaded 22 April 2009]. 18)Charan J, Yadav P, Saxena D, Kantharia ND. Drug advertisements published in Indian Medical Journals: Are they ethical?J Pharm Bioallied Sci. 2011 Jul;3(3):403-6.

19)Oshikoya KA, Senbanjo IO, Soipe A. Adequacy of pharmacological information providedin pharmaceutical drug advertisements in African medical journals. Pharm Pract 2009;7:100-7.

20)World Health Organization. Geneva: World Health Organization; 1988. Ethical criteria for medicinal drug promotion. Available from: http://www.who.int/medicinedocs [downloaded 3 August 2008].

21)Kar SS, Pradhan HS, Mohanta GP. Concept of essential medicines and rational use in public health. Indian J Community Med. 2010 Jan;35(1):10-3.

22)Sherif F. An Evaluation of the Prescribing Patterns of Drugs in Libya. JMJ, 2008; 18(3):

203-6.

23)Katakam P, Elfituri AA, Ramadan $Z H$, AbadiA G. Retrospective Study on Antibiotic Use in Different Clinical Departments of a Teaching Hospital in Zawiya, Libya.Ibnosina $\mathbf{J}$ Med BS. 2012;4(1):13-19.

24)Zoutman DE, Douglas Ford B, Bassili AR, Cosby JL, Nakatsu K.Factors Affecting Antibiotic Decisions: a Survey of Family Physicians Concerning the Use of Antibiotics to Treat Upper Respiratory Tract Infections. Int J Infect Contr. 2008;4(1).

25)Odonkor ST, Addo KK. Bacteria resistance to antibiotics: recent trends and challenges.Int $\mathrm{J}$ Biol Med Res. 2011;2(4):1204 -10.

26)Morgan SG, Bassett KL, Wright JM, Evans RG, Barer ML, Caetano PA, Black CD. "Breakthrough" drugs and growth in expenditure on prescription drugs in Canada.BMJ. 2005 Oct 8;331(7520):815-6.

27)Steinman MA, Harper GM, Chren MM, Landefeld CS, Bero LA. Characteristics and impact of drug detailing for gabapentin. PLoS Medicine / Public Library of Science. PLoS Med. 2007:4(4):e134

28)Kerr SJ, Mant A, Horn FE, McGeechan K, Sayer GP. Lessons from early large-scale adoption of celecoxib and rofecoxib by Australian general practitioners.Med J Aust. 2003 Oct 20;179(8):403-7.

29)Hawkes N. GlaxoSmithKline pays $\$ 3$ bn to settle dispute over rosiglitazone and other drugs. BMJ. 2011.

30)Alssageer MA, Kowalski SR. Doctors' opinions of information provided by Libyan pharmaceutical company representatives.Libyan J Med. 2012;7.

31)Cooper RJ, Schriger DL. The availability of references and the sponsorship of original research citedin pharmaceutical advertisements.CMAJ. 2005 Feb 15;172(4):487-91.

32)Mejía R, Avalos A. Printed material distributed by pharmaceutical propaganda agents.Medicina (B Aires). 2001;61(3):3158.[Article in Spanish].

33)Alam K, Shah AK, Ojha P, Palaian S, Shankar PR. Evaluation of drug promotional materials in a hospital setting in Nepal. South Med Rev. 2009 Apr;2(1):2-6.Epub 2009 Apr 16. 34)Othman N, Vitry A, Roughead EE. Quality of pharmaceutical advertisements in medical 
journals: a systematic review. PLoS One. 2009;4(7):e6350.

35)Lexchin J, Holbrook A. Methodologic quality and relevance of references in pharmaceutical advertisements in a Canadian medical journal. CMAJ. 1994 Jul 1;151(1):47-54.

36)Lankinen KS, Levola $T$, Marttinen $K$, Puumalainen I, Helin-Salmivaara A. Industry guidelines, laws and regulations ignored: quality of drug advertising in medical

37)journals.Pharmacoepidemiol Drug Saf. 2004 Nov;13(11):789-95.

38)Lexchin J, Bero LA, Djulbegovic B, Clark O. Pharmaceutical industry sponsorship and research outcome and quality: systematic review.BMJ. 2003 May 31;326(7400):1167-70.

39)Heimans L, van Hylckama Vlieg A, Dekker FW. Are claims of advertisements in medical journals supported by RCTs?Neth J Med. 2010 Jan;68(1):46-9.

40)Mali SN, Dudhgaonkar S, Bachewar NP. Evaluation of rationality of promotional drug literature using World Health Organization guidelines.Indian J Pharmacol. 2010 Oct;42

(5):267-72.

41)Gutknecht DR. Evidence-based advertising?

A survey of four major journals.J Am Board Fam Pract. 2001 May-Jun;14(3):197-200.

42)Figueiras A, Caamaño $F$, Gestal-Otero JJ. Influence of physician's education, drug information and medical-care settings on the quality of drugs prescribed.Eur $\mathrm{J}$ Clin Pharmacol. 2000 Dec;56(9-10):747-53.

43)Mick, DG. "Levels of Subjective Comprehension in Advertising Processing and Their Relations to Ad Perceptions, Attitudes, and Memory," Journal of Consumer Research.1992;18:411-424.

44)Legge GE, Bigelow CA. Does print size matter for reading? A review of findings from vision science and typography. J Vis. 2011 Aug 9;11(5). pii: 8 .

45)Berger IE, Mitchell AA. The effect of advertising on attitude accessibility, attitude confidence, and the attitude-behavior relationship. Journalof Consumer Research. 1989; 16:269-279.

46)Cacioppo JT, Petty RE. Effects of message repetition and position on cognitive response, 47)recall and persuasion. Journal of Personality and Social Psychology. 1979;37(1):97-109.

48)Haas JS, Phillips KA, Gerstenberger EP, Seger AC. Potential savings from substituting generic drugs for brand-name drugs: medical expenditure panel survey, 1997-2000. Ann Intern Med. 2005 Jun 7;142(11):891-7.

49)Steinman MA, Chren MM, Landefeld CS. What's in a name? Use of brand versus generic drug names in United States outpatient practice. J Gen Intern Med. 2007 May;22 (5):

645-8.

50)U.S. Department of Health and Human Services. Guidance for Industry Product Name Placement, Size, and Prominence in Advertising and Promotional Labeling.2012. available from

http://www.fda.gov/downloads/Drugs/.../Guidan ces/ucm070076.pdf.

51)McQuarrie EF, Mick DG. "On Resonance: A Critical Pluralistic Inquiry into Advertising Rhetoric," Journal of Consumer Research. 1992;19(2):180-197.

52)Paivio A. A Dual Coding Approach to Perception and Cognition. In: Pick H, Saltzman E, editors. Modes of Perceiving and Processing Information Lawrence Erlbaum Associates: Hillsdale. NJ: 1978. p. 39.:39-51.

53)McKelvie SJ, Demers EG. Individual differences in reported visual imagery and memory performance.Br J Psychol. 1979 Feb;70(1):51-7.

54)Goodstein C. Category-Based Applications and Extensions in Advertising: Motivating More Extensive Ad Processing, Journal of Consumer Research. 1993;20(1):87-99.

55)Norris $P$, Herxheimer A, Lexchin J, Mansfield P. Drug Promotion: What we know, what we have yet to learn. Geneva: World Health Organisation 2005

http://www.haiweb.org/18012006/drugPromodh ai12sept.pdf.

56)Wazana A. Physicians and the pharmaceutical industry: is a gift ever just a gift? JAMA. 2000;19;283(3):373-80. 
APPENDIX1. LIST OF PROMOTED DRUGS IN PCRS BROCHURES

\begin{tabular}{|c|c|c|c|}
\hline 1 & Glimepiride (4) & 67 & Domperidone \\
\hline 2 & Glimepiride/metformin & 68 & Metformin/ Glibenclamide \\
\hline 3 & Clomiphene & 69 & Valsartan(3) \\
\hline 4 & Loperamide & 70 & Indapamide \\
\hline 5 & Bromohexine & 71 & Lansoprazole \\
\hline 6 & Irbesartan & 72 & Ceftizoxime \\
\hline 7 & Ibuprofen(2) & 73 & Gliclazide \\
\hline 8 & Azithromycin(4) & 74 & Piroxicam(3) \\
\hline 9 & Salicylic A, lactic A, polidocanol & 75 & Cefditoren. \\
\hline 10 & Ranitidine & 76 & Cefixime \\
\hline 11 & Calcipotriol $\backslash$ betamethasone. & 77 & Cefdinir \\
\hline 12 & $\alpha$-Glucosamine / Ginkgo/ Biloba & 78 & Moxifloxacin \\
\hline 13 & Salbutamol & 79 & Methyprednisolone \\
\hline 14 & Ketoprofen (2). & 80 & Isoflurane \\
\hline 15 & Mesalazine & 81 & Naproxen \\
\hline 16 & Salmeterol/ fluticasone & 82 & Alginic acid/colloidal aluminium hydroxide / magnesium hydroxide \\
\hline 17 & Fusidic acid & 83 & Policresulen \\
\hline 18 & Betamethson, Tolnaftate, Clioquinol, Gentamycin & 84 & Methotrexate \\
\hline 19 & Ciproflaxacin(4) & 85 & Gentamicin \\
\hline 20 & Etoricoxib & 86 & Ofloxacin(2) \\
\hline 21 & Meloxicam & 87 & Ornidazole \\
\hline 22 & Nifedipine $(2$ & 88 & Acarbose(2) \\
\hline 23 & Anastrozole(2) & 89 & Amoxycillin \\
\hline 24 & Goserelin & 90 & Bisoprolol \\
\hline 25 & Bicalutamide/ Goserelin & 91 & Levofloxacin \\
\hline 26 & Diclofenac (5) & 92 & Paracetamol/chlorpheniramine/pseudoephedrineGuaifenesinpseudophedrine \\
\hline 27 & Risedronate & 93 & Codeine \\
\hline 28 & Meclozine/ Pyridoxine & 94 & Simvastatin (2) \\
\hline 29 & Clopidogrel (4) & 95 & Trimebutin \\
\hline 30 & Esomeprazole (2). & 96 & Mebeverine \\
\hline 31 & Amoxicillin/ clavulanic acid (9). & 97 & Vancomycin \\
\hline 32 & Dextromethorphan & 98 & Imidapril. \\
\hline 33 & Thiocolchicoside & 99 & Donepezil \\
\hline 34 & Omeprazole(5) & 100 & Micronized \\
\hline 35 & Pancreatic enzyme substitution & 101 & Vitix(12combination). \\
\hline 36 & Candesartan 12 & 102 & Isosorbidedinitrate \\
\hline 37 & Amlodipine(4) & 103 & Betamethasone/neomycin \\
\hline 38 & Eprosartan & 104 & Metronidazole \\
\hline 39 & Atorvastatin(5) & 105 & Carvedilol \\
\hline 40 & Pioglitazone/ Metformin & 106 & Olmesartan /plus(HCZ) \\
\hline 41 & Rosuvastatin(2)12 & 107 & Lisonopril \\
\hline 42 & Enoxaparin & 108 & Recombinant Human Granulocyte Colony-stimulating Factor(Rh-G-CSF) \\
\hline 43 & Clarithromycin(7) & 109 & Mesalamine \\
\hline 44 & Flucloxacillin/ Amoxicillin & 110 & Felodipine \\
\hline 45 & Cefuroxime(3) & 111 & Meropenem \\
\hline 46 & Diclofenac/methocarbamol & 112 & Alfuzosine \\
\hline 47 & Gemifloxacin & 113 & Tinzaparin \\
\hline 48 & Prifiniumbromid & 114 & Alfacalcidol \\
\hline 49 & Dexmethasone & 115 & Ursodeoxycholic acid \\
\hline 50 & Lyophilized Fish Roe/Ginkobiloba & 116 & Fexofenadine \\
\hline 51 & Pantoprazole (2) & 117 & Metformin. \\
\hline 52 & Ketoconazole $(2)$ & 118 & Lactulose \\
\hline 53 & Candesartan/ hydrochlorothiazide & 119 & Roxithromycin \\
\hline 54 & Calcium analogues and others & 120 & Dexchlorpheneramine/ pseudoephedrie/ guaifenesin \\
\hline 55 & Polymyxin B, Neomycin, Dexamethasone & 121 & Dimenthindene \\
\hline 56 & Doxycyclin & 122 & rh-Erythropioietih \\
\hline 57 & Ceftazidime & 123 & Metoclopramide \\
\hline 58 & Itraconazole & 124 & Dextromethorphan/ Guaifenesin / Menglycate \\
\hline 59 & Sulbactam/ Ampicillin & 125 & Mometasone \\
\hline 60 & Progesterone & 126 & Buflomedil \\
\hline 61 & Levocetirizine & 127 & Losartan \\
\hline 62 & Lipidosterolic extract of Serenoarepens & 128 & Dorzolamide/ Timolol \\
\hline 63 & Ibuprofen/ Levometenthol & 129 & Phloroglucinol,Trimethylphloroglucinol \\
\hline 64 & Chondroitin sulphate & 130 & Guaifenesinpseudophedrine \\
\hline 65 & Oral Clostridium,Butyricum\&bifidobactrium & 131 & Fondaparinux \\
\hline 66 & Benproperine & 132 & Dinoprostone \\
\hline
\end{tabular}




\section{APPENDIX2. EMOTIONAL WORDS AND PHRASES (RHETORIC, METAPHORIC AND HYPERBOLIC) IN PCRS BROCHURES}

\begin{tabular}{|c|c|c|c|}
\hline 1 & Nausea and vomiting not any more & 39 & gain power and vitality, \\
\hline 2 & Golden standard for a healthy life. & 40 & for a best power, \\
\hline 3 & the Sunshine $\mathrm{X}$ & 41 & ensures clear benefits, \\
\hline 4 & Xdrug can explore the heart of underwater region, & 42 & the truth about otitis media, \\
\hline 5 & let him walk again without the cane, & 43 & efficacy shaped in convenience, \\
\hline 6 & soothing the stream of fire, & 44 & unmatched pain killing strength, the top of the relief, \\
\hline 7 & power on target, & 45 & "Xdrug the standard and still the best", \\
\hline 8 & the prime choice is Xdrug successful, & 46 & sweet balance, \\
\hline 10 & "STOP", & 48 & the best known, \\
\hline 11 & Starting where other end, & 49 & rewarded quality, \\
\hline 12 & the fastest way to relief, & 50 & "Happiness is gold.. don't rob the moment", \\
\hline 13 & power of the king, & 51 & "can't hit pathogens any harder", \\
\hline 14 & no wasted shots full control, & 52 & only the best reaches the top", \\
\hline 15 & maximum protection, & 53 & I can breathe easier with X drug", \\
\hline 16 & let her live, & 54 & "control beyond cholesterol", \\
\hline 17 & evidence of CV benefits with Jupiter, & 55 & "an expert's choice", \\
\hline 19 & "Fast.. Slow Together can Go", & 57 & start on winning note, \\
\hline 20 & fire prevention, & 58 & play the right card, \\
\hline 21 & efficacy you can depend on, & 59 & hit the right target, \\
\hline 22 & clearly different, & 60 & Stop existing...start living, \\
\hline 23 & "the rabbit rapid", & 61 & "experience the drop reach the goal", \\
\hline 24 & "you can rely on", & 62 & Need to lower your pressure?, \\
\hline 25 & "the power you can trust to work day after day", & 63 & mastering the common pathogens, \\
\hline 26 & "First time recovery", & 64 & cutting edge antibiotics, \\
\hline 27 & "blow your dandruff away", & 65 & fitted to your patients \\
\hline 28 & on the right level you'll get further", & 66 & make life more streamlined, \\
\hline 29 & keeping the balance, & 67 & proven safety, \\
\hline 30 & "unity is strength..", & 68 & "No cri! Just comply", \\
\hline 31 & the ultimate feeling of relief', & 69 & "bring down your cholesterol", \\
\hline 32 & "health is real wealth", & 70 & do today's allergic require a potent treatment?' \\
\hline 33 & "the fastest way to relief", & 71 & FDA approved \\
\hline 34 & 'omeprazole the real PPI', & 72 & , powerful yet kind, \\
\hline 35 & the strongest link, & 73 & newest oral proton pump inhibitors \\
\hline 38 & the ideal solution, & 76 & your direction in anticoagulant \\
\hline
\end{tabular}

